\title{
El ejercicio de la corrección: lectura del manuscrito de La lección de pintura, de Adolfo Couve*
}

\author{
Pablo Chiuminatto** \\ Felipe Toro ${ }^{* * *}$
}

\begin{abstract}
Resumen
Teniendo en cuenta la estricta composición formal que caracteriza gran parte de la obra narrativa de Adolfo Couve, en este artículo revisamos el manuscrito de La lección de pintura (1979) y sus principales enmiendas, proponiendo un paralelo entre los ejercicios de la corrección del autor ("aprendiz" de realista) y el camino de aprendizaje de un niño genio de provincia (aspirante a pintor neoclásico) que es narrado en esta nouvelle. En la medida en que La Lección de pintura se pregunta por cómo pintar, y cómo escribir, desde Chile en relación a la herencia europea, también dialoga con las preocupaciones y los modos de representación en el arte y la literatura que animarán, más tarde, La comedia del arte (1995) - nouvelle en que el narrador nuevamente se identificará con un niño, pero ya no con un aprendiz que debe ser corregido.
\end{abstract}

Palabras clave: Adolfo Couve, manuscritos, crítica genética, arte y literatura.

\section{The art of correction: reading Adolfo Couve's manuscript of La lección de pintura}

\begin{abstract}
Considering the strict literary composition that characterizes a large part of Adolfo Couve's narrative work, in this paper we read the manuscript of La lección de pintura (1979) and its major amendments, proposing a parallel between the corrections carried out by the author (an "apprentice" of realist tradition, in his own words) and the coming-of-age story about a boy genius (an aspiring neoclassical painter) located within the Chilean provincial life that this novella relates. Insofar as La lección de pintura inquires about how to paint, and how to write from Chile in relation to European cultural heritage, it dialogues as well with the issues and modes of representation in art and literature that will be later at stake in $\mathrm{La}$ comedia del arte (1995) - a novella in which Couve's narrator will again identify himself with a child, but no longer with an apprentice that has to be corrected.
\end{abstract}

Key words: Adolfo Couve, manuscripts, genetic criticism, art and literature

Recibido: 27-08-2013 Aceptado: 29-10-2013

\footnotetext{
* Este trabajo forma parte de una investigación acerca de los manuscritos de Adolfo Couve y se asocia al proyecto CCA2013-1491, Vicerrectoría de Investigación, Pontificia Universidad Católica de Chile.

** Chileno, Doctor en Filosofía, Universidad de Chile. Profesor Asociado, Pontificia Universidad Católica de Chile, Santiago, Chile, pchiuminatto@uc.cl

*** Chileno, Magíster en Literatura, Universidad de Chile, felipetorofranco@gmail.com
} 
Quizá algún día los lectores de un narrador como Adolfo Couve, que situó el ejercicio de la corrección en el centro de su poética, merezcamos leer la edición de sus textos con todos sus borrones y tachaduras incluidos, con todas las huellas y materiales que el escrupuloso rigor formal suprimió como cuerpos indeseados. Y es que la armónica fragilidad de sus obras, semejantes a modelos hechos con "palitos de fósforos" ( $E l$ cumpleaños 299), hace preguntarse constantemente por el severo taller de la escritura del que provienen. El mismo Couve señalaba con el énfasis propio de un manifiesto en el prólogo a Cuarteto de la infancia (1996), esa "retrospectiva" de sus relatos centrados en la niñez: " [q]uería alcanzar una prosa depurada, convincente, clara, distante, impersonal, unos renglones donde tuviera que corregir y corregir, aprender a hacer bien la tarea, leerlos en voz alta, castigar el contenido y el lenguaje..." ("Prólogo" 8).

No deberíamos dejar pasar esa expresión tan pedagógica, tan infantil, hacer bien la tarea, que emparenta el trabajo del narrador con los silenciosos pupilos que pueblan sus relatos ("Allí, el niño en el mesón junto al pupitre de su madre aprendía a trazar palotes y vocales" [La lección de pintura 184]); y que invita a concebir sus brevísimos textos como delicados ejercicios de caligrafía en los que el "aprendiz de realista" ("Prólogo" 9), cual niñito obediente, pasa en limpio, de nouvelle en nouvelle, una misma escena o una misma letra ${ }^{2}$. Y dicho sea de paso, Couve siempre escribió a mano, y sus manuscritos, salvo contadas excepciones, están redactados en cuadernos escolares (cuadernos de composición) que no alcanzan las cien hojas. Nos convocan precisamente esos cuadernos -el tesoro de los manuscritos de Couve, conservados en la Biblioteca Nacional, sin haber recibido atención crítica- a leer el revés de la corrección, a descifrar los procesos germinales de una escritura que se jactaba del autocontrol y la economía de medios; en suma, a asomarse a los caminos que fueron castigados o clausurados.

El énfasis radical en la corrección resulta todavía un aliciente más para interrogar esos fragmentos excluidos contra los cuales la prosa de

1 Se trata de El picadero (1974), El tren de cuerda (1976), La lección de pintura (1979), El Pasaje (escrita a partir de 1977, pero publicada en 1989).

2 Si la crítica ha reparado que todos los personajes infantiles de Couve llevan por nombre una A de Adolfo (Valdés “Adolfo Couve" 10), recordemos que es en el cuaderno de caligrafía donde los niños ensayan, una u otra vez, la misma letra. 
Couve se rebeló con encono implacable, con una exageración que hacía preguntarse qué estaba por debajo o qué se buscaba acallar con ese esmero letal, como si se trataran de fantasmas que acechaban la cara bruñida de su sintaxis de orfebre. Precisamente, uno de los títulos tentativos para lo que terminó llamándose El tren de cuerda (1976) fue El cadáver del orfebre. ¿Acaso siempre la puntillosa labor del artesano conlleva una cuota de su muerte, el riesgo del cadáver, la propia obra aniquilada en el proceso de perfeccionarse? Ante los manuscritos de Couve, vale la pena recordar las palabras con que Lois Hay -imprescindible figura de la llamada crítica genética- definió la tarea de la crítica con respecto a lo que más tarde se ha denominado el estudio de los avant-textes:

Aspirando a descubrir una pluralidad de textos virtuales debajo de la superficie del texto ya constituido, esta crítica se encuentra claramente ligada a una literatura contemporánea en busca de formas abiertas, atenta a lo que Julie Green describió como la "novela que pudo haber sido", a elementos que siempre están latiendo en la novela existente, y a lo que Julien Gracq ha llamado los "fantasmas de sucesivos libros" que han quedado en el camino y que por siempre rondan las composiciones terminadas ("Genetic criticism" 22; traducción y énfasis nuestros).

Tanta es la persistencia con que estos fantasmas rondan la escritura de Couve, que finalmente aparecerán jugando un papel medular y visible dentro del engranaje narrativo de su última novela publicada en vida, La comedia del arte (1995). Tardía obra maestra, se abre escenificando paródicamente los devaneos de la corrección: "Es la tercera vez que intento este relato, esta tragedia, esta parodia. Antes fracasé" (Couve 363). Nada extraño, viniendo de un narrador cuyo panteón literario estaba encabezado por Flaubert, a quien de seguro siguió en los tormentos del estilo, pudiendo como pocos suscribir al contenido de la famosa carta que el maestro escribió a Louise Colet en 1852: "Cuando mi novela esté terminada, dentro de un año, te llevaré mi manuscrito completo, por curiosidad. Verás por medio de qué mecánica complicada consigo hacer una frase" (Correspondencia, sin núm.) ${ }^{3}$.

3 Curiosamente, dentro de los mayores aportes de la crítica genética están los estudios dedicados a los manuscritos de Flaubert (Williams 165), cuyos ideales de composición no están demasiado lejos de los esfuerzos de nuestro "aprendiz de realista", como se autodefinió Couve. En cuanto a la filiación de Couve y Flaubert, remitimos a "El síndrome de Flaubert", de Adriana Valdés. 
Mecánica tortuosa de la que precisamente la prosa de Couve pareciera recién haberse podido liberar en La comedia del arte, al enfrentarse con ironía a los residuos de la corrección y dejarlos deslizarse ficcionalmente en el relato: "Creo [...] que a esta descripción [...] añadí una poética relación de las olas que se ven al fondo de esa extensa playa de arena negra. La que decía: 'Reventaban en silencio como el graznar mudo de las gaviotas lejanas'” (364). De alguna manera, el gesto de esta postrera inclusión de lo tachado consigue un efecto similar a la lectura de los manuscritos de Couve: el acceso a "una tercera dimensión", diría Hay ("Does 'text' exist?", 75), como si la escritura de pronto se pusiera en perspectiva y pudiera leerse por capas la historia de su evolución; un pentimento de la letra, podríamos llamarlo, tomando el término de las huellas que quedan de las sucesivas etapas de composición de una pintura. ¿Cómo negarse a la lectura de estos manuscritos, cuando los mismos textos de Couve parecen fantasear con la idea de ser contrastados con su propio borrador? ${ }^{4}$

De este modo, el tardío alivio de las exigencias del estilo que supone La comedia del arte, quizás sea el mejor lugar para mirar hacia atrás y pesquisar los caminos de la corrección de sus obras anteriores. Alivio, agreguemos, que se encuentra asombrosamente descrito en un párrafo eliminado de la apertura de La comedia, y que ahora adquiere el tono de una confesión, de una toma de conciencia del giro que estaba dando su narrativa. Revisémoslo para terminar de situar nuestra lectura y por el innegable valor del manuscrito y sus correcciones para comprender las transformaciones de la poética de Couve:

Al revisar lo escrito siento una gran liberación, me siento rejuvenecer, al fin he sido capaz de superar tanta literatura, me acontece (con harta distancia) lo que a Ticiano y a Miguel Angel que en sus obras tardías pintaba al revés, aparentemente mal, como buscando en esa consciente desintegración, avidez de color y poner el acento en donde no debía, restaurar el equilibrio consigo mismo. No olvidemos que Picasso dijo expresó que debíamos con gran esfuerzo lograr algún día

4 Además, según testimonio de Pedro Pablo Zegers, jefe del Archivo del Escritor de la Biblioteca Nacional, fue el propio Couve, unas semanas antes de su muerte, quien donó personalmente sus manuscritos, previamente organizados y clasificados por él mismo. 
dibujar como niños (Manuscrito de La comedia del arte, sin núm.; conservamos ortografía y puntuación).

Aquella imagen que leíamos del pupilo haciendo bien la tarea bajo la vara flaubertiana, se ubica en las antípodas de esta verdadera Lección de Picasso, donde el celo disciplinante se "desintegra" ("pintaba al revés, aparentemente mal"). Ahora libre de castigos, el otrora "aprendiz de realista" decide en su Comedia entrar, como niño sin tareas, al Cielo del Dante, habitado por los maestros Tiziano y Miguel Ángel, y no por nada alcanzado sólo al tercer intento ("Es la tercera vez que intento este relato..." [La comedia del arte 363]). Resulta imposible para el lector de Couve evitar la comparación entre esta gozosa escena de la escritura y los esfuerzos estilísticos de esa otra discusión sobre las condiciones del arte en la provincia que es La lección de pintura (1979), escrita cuando sus escenas de aprendizaje de la infancia parecían trabajadas bajo el lema de la letra con sangre entra.

Desde este contrapunto quisiéramos situar nuestra primera revisión del manuscrito de La lección de pintura, contrastando la visión paródica y celestial del narrador final -que se permite las licencias de los grandes genios del arte-, con las "pruebas" de oficio en las que debió foguearse un talentoso, aunque sufrido, "aprendiz de realista". Sugerentemente, el protagonista de La lección de pintura se encargará de replicar la posición discipular del narrador de entonces, pues se trata de la modesta vida del promisorio "aprendiz de pintor" Augusto Medrano, a quien seguimos desde su más tierna infancia hasta que lo vemos con un "incipiente bigote y una pelusa en las mejillas" (192), recibiendo su primera instrucción formal en una academia de arte de la ciudad de Viña del Mar.

Nada más distante en procedimientos que La lección de pintura y La comedia del arte, aunque probablemente estas sean las dos obras de Couve que han recibido mayor atención, y no en vano ambas abordan con veinte años de diferencia el mismo nudo existencial del pintor perdido en la provincia: la primera desde la infancia huérfana, la segunda desde la soledad de la vejez. Nada más distante, decíamos, porque mientras La comedia del arte abrazaba el dictado de Picasso acerca de olvidar lo aprendido, en el manuscrito de La lección de pintura, leemos que su primer título tentativo fue el de La vida secreta de un pintor neoclásico (proyecto de novela que Couve parece haber acariciado largamente, insinuándolo y luego posponiéndolo, como dan cuenta los cuadernos del 
manuscrito de El parque [1976], precisamente su obra anterior). La vida secreta de un pintor neoclásico, título que podríamos suponer en abierta polémica con La vida secreta de Salvador Dalí (1942), la autobiografía del pintor surrealista. Frente a la sobreexposición de las vanguardias del siglo XX y sus gestos grandilocuentes, el narrador de Couve propone el tono menor del trazo vital de un niño genio, la anécdota minúscula como ejercicio de falsa modestia, la mirada vuelta hacia la tradición. Además, ¿no se sitúa ese ser completamente silencioso, Augusto Medrano, en el brumoso territorio de la novela autobiográfica, del testimonio velado que recupera la infancia 5

La vida secreta de un pintor neoclásico: el título tachado sin duda hará recordar también las reflexiones del propio Couve sobre los modelos de su escritura "realista", las fantasías proyectadas en la propia obra: "El período [entre los dos Napoleones] contó también con grandes pintores; [...] [se] requirieron testimonios convincentes, como el de David e Ingres, o sea una escuela, la neoclásica, quizá un tanto escenográfica, pero cargada de poesía, ingenuidad y afán de organizar un mundo autónomo" ("Prólogo" 8). Ejercicio de traducción que va del realismo literario al neoclasicismo pictórico: ¿será equivalente, en el la ley de valores del mundo de Couve, decir La vida secreta de un pintor neoclásico a La vida secreta de un escritor realista? Y, por cierto, nuestro título fantasma ilumina una de las escenas más notables del relato, el desencuentro del pequeño Augusto con su protector Carlos Aguiar, farmacéutico aficionado a la pintura. Cuando contra todas las expectativas, al visitar el Museo Nacional de Bellas Artes, Augusto se deslumbra con una tela de Monvoisin", ante lo que el tutor responde descontrolado: “¡Aquello es pintura neoclásica, literatura, porquería, basura! [...] Monvoisin... un pintor de segundo orden, compañero de Ingres, otro porfiado" ( $\mathrm{La}$ lección de pintura 190). Casi quince años antes del prólogo-manifiesto

5 Recurramos, en una primera instancia, al problemático sitial que la nomenclatura de Philippe Lejeune -basada en la coincidencia del nombre propio del autor con el del personaje- da a la "novela autobiográfica": "[L]lamaré así a todos los textos ficcionales en los cuales el lector puede tener razones para sospechar, a partir de parecidos que cree percibir, que se da una identidad entre el autor y el personaje, mientras que el autor ha preferido negar esa identidad o, al menos, no afirmarla [...]. A diferencia de la autobiografía, implica gradaciones. El "parecido" supuesto por el lector puede ir de un "vago aire de familia", hasta la casi transparencia que lleva a concluir que se trata del autor 'clavado'" (52).

6 Pintura que parece un mensaje cifrado, cual alegoría escondida en una miniatura, para la coyuntura de la época: "[r]epresentaba el 9 de Thermidor, día en que Robespierre cayó en desgracia. Se veía al líder de los jacobinos desesperado en su intento de acallar a los insurgentes" (190); luego el niño preguntará: “-¿Quién era Robespierre?- ¡Otra vez! Un tirano, un dictador....” (191; énfasis nuestro). 
de Cuarteto de la infancia, ya estaba presente, en el arrebato visceral del farmacéutico, el "porfiado" encadenamiento entre pintura neoclásica y literatura: ¿no son tal vez señas de un oficio que, abandonando la mancha, decide acercarse a la escritura?

Como sea, esta literatura que goza de los contrastes nacionales, de los descalces más brutales entre el paisaje y sus habitantes (al extremo de situar más adelante al mismísimo dios Apolo en el balneario de Cartagena), pareciera aquí preguntarse, con un malicioso sentido del humor: ¿qué pasaría si entre nosotros, sin merecerlo, tuviéramos a un artista de la talla de un Ingres, un David, o en última instancia -porque hacia allá va la pregunta sin disimularlo demasiado- un Couve?, ¿no lo prohijaría un farmacéutico pueblerino, parodia local del connoisseur d'art, un tanto siútico? La vida secreta de un pintor neoclásico: vida "secreta" -conjeturamos- por la oscura existencia de su protagonista en un escondido pueblo camino a San Felipe: Llay-Llay. Aunque encima de esas locaciones en el manuscrito vislumbramos borroneados los nombres de las localidades de Faleamávida y Ehiguayante, es decir, en un inicio el escenario se situó cerca de mil kilómetros más al sur, pero siempre connotando una distancia con los centros urbanos, arrimándose al terruño, a las vidas mínimas, perdidas en el mapa -en fin, donde con sólo nombrar la provincia se sugiere un mismo aislamiento ${ }^{7}$.

Sin embargo, al observar la vida liliputiense y pueblerina de LlayLlay, que Couve describe con oficio de miniaturista, el lector comienza a sospechar que esta representación, más que un retrato verista, corresponde a una cómica puesta en escena de los referentes de la educación artística chilena y, en especial, de nuestras academias de arte. Leemos acerca del farmacéutico Carlos Aguiar: "[Su dedicación a las actividades artísticas], le significaba emprender continuos viajes a Santiago, ya que los espectáculos del pueblo le resultaban tediosos" (176). Pero, ¿qué son las galerías de arte y las funciones de ópera de Santiago en comparación a las de Roma, Londres o, especialmente, París? ¿No son, las nuestras, modestas copias de yeso, como aquellas cuyo traslado gestionó Monvoisin en el siglo XIX para el Bellas Artes y que Couve se encargaría más tarde de novelar en un relato homónimo? Desde aquí, ¿no comienzan a diluirse

7 Recordemos que la misma etimología de provincia remite a un lugar ya vencido, subyugado por la fuerza (pro-victa). Aunque en el caso de Couve, como veremos, tampoco es que transforme a la capital en la cabeza del imperio. 
las diferencias, no comienza Santiago a tomar los colores de Llay-Llay? Acercar y alejar la mirada: en ese mosaico de pequeñeces que es la vida cultural de Llay-Llay, con sus improvisadas tertulias en la droguería del pueblo, con sus orgullos ridículos ("cuando alguno de los invitados interrumpía para contar un detalle que al parecer el señor Aguiar había omitido, éste lo silenciaba con una mirada de hielo..." [177]), se nos presenta el panorama artístico de la nación completa, reducido a escala en un gracioso, pero también patético microcosmos rural. En este sentido, el arte de la nouvelle de Couve consiste también en alterar las proporciones hasta la exageración, para ofrecer un calculado juego de perspectivas: "No hay miniaturas en la naturaleza; la miniatura es un producto cultural, el producto de un ojo realizando ciertas operaciones, manipulando [...] el mundo físico" (Stewart, On longing, 55; traducción y énfasis nuestros) ${ }^{8}$.

No resulta extraño, entonces, que en las escenas de aprendizaje de La lección de pintura surjan figuras sospechosamente familiares a las de la Escuela de Bellas Artes de la Universidad de Chile ${ }^{9}$, camuflados entre los lugareños de Llay-LLay y sus alrededores. Señas significantes que invitan a leer como si se tratara de un roman à clef ${ }^{10}$, como si el narrador fuera un niño travieso que hace caricaturas de los familiares y seres queridos, transportándolos a realidades peregrinas, componiendo de este modo un cuadro paródico de la familia del arte. Así, vemos que entre quienes asisten a las tertulias hay un "un viejo alemán que había vendido la droguería a su actual dueño..." (180), de apellido "Bechard" (181). Este nombre nos recuerda, casi transparentemente, por afinidad formal,

8 A estas operaciones nos hemos referido en otro lugar (“Una pieza secreta: juegos y juguetes en la narrativa de Adolfo Couve), pero baste recordar que el título de uno de sus opúsculos, El tren de cuerda, cuyo referente de inmediato se pierde en la anécdota del texto, desde ya pareciera indicarnos esta novela es el tren de cuerda, o mejor dicho, esta es una novela de juguete.

9 Para un panorama histórico de la Escuela de Bellas Artes junto a sus figuras más prominentes, remitimos aquí al artículo "Educación artística en Chile: Fernando Álvarez de Sotomayor, Juan Francisco González y Pablo Burchard, tres maestros emblemáticos" (2007), de Pedro Zamorano Pérez. Sobre su estrecha relación con la Universidad de Chile, apunta: “En el año 1929, por Decreto Supremo, la Escuela de Bellas Artes, que transitoriamente había dependido del Ministerio de Instrucción Pública, pasó a depender de la Universidad de Chile" (192).

10 Leyendo ciertamente bajo el influjo de El placer del texto de Roland Barthes y problematizando el sistema de clasificación de Philippe Lejeune, Sean Latham en The art of scandal: modernism, libel law, and the roman à clef (2009) rescata el roman à clef por el papel protagónico que le cabe a las condiciones de circulación del texto, y reivindica la intuición del lector de estar frente a una literatura que remite más allá de sí misma: "Por un lado, puede utilizar estratégicamente las convenciones de la novela -incluyendo un énfasis casi obsesivo en la descripción detallada- para pasar por ficción. Por otro, para aquellos que poseen (o imaginan poseer) la clave, estos mismos elementos textuales se transforman de simulacro realista en hechos verídicos acerca de gente real. Además, a diferencia de las memorias o el diario, el roman à clef por definición depende de sus condiciones de recepción y circulación" (9; traducción nuestra). 
al de don Pablo Burchard (1875-1964), pintor de enorme influencia en las nuevas generaciones de artistas que se formaron en la Escuela de Bellas Artes, y maestro de Couve ${ }^{11}$."De mostachos amarillentos, por el exceso de cigarros, hablaba con una voz meliflua que contrastaba con la gravedad de su aspecto", anota el narrador de La lección de pintura (182). Si no es por el nombre, ¿debemos reconocerlo por el bigote?

Por cierto, no está en nuestra intención forzar una lectura referencial, sino más bien señalar que buena parte del texto está programado para conseguir ese tipo de asociaciones; la misma nouvelle difumina los límites y alienta al lector a buscar el modelo de la caricatura. Sobre todo si consideramos que los primeros lectores de esta nouvelle no eran en absoluto incapaces de reconocer las semejanzas deliberadas, porque se trataba ni más ni menos que de los miembros de la comisión del Departamento de Teoría del arte de la Universidad de Chile ante los que Couve presentó este relato como Tesis de Licenciatura (1979). ¿Son ellos los lectores ideales de estas parodias afectivas, prontos a descubrir las alusiones en este ambiguo homenaje?, ¿por qué, entonces, resistirse a leer el texto desde las huellas de su circulación inmediata y su público directo? Doble travesura (o rebeldía), pues si por una parte el color local de Llay-Llay reviste a los personajes conocidos de una aureola de comicidad, por otra los vuelve literalmente "provincianos", los descalifica en su idoneidad para conducir los primeros pasos del pequeño genio que vive entre ellos: "Entonces se sucedían expresiones como 'pintores llenos de luz y movimiento', 'cuadros hechos con nada' y frases por el estilo que hacían creer a los demás que el señor Aguiar no sólo era un hombre informado, sino que también conocía más allá de las biografías, el contenido intrínseco de esas escuelas" (178). ¿No es esta la imitación de una cátedra, con todos sus tics, igual que cuando niños jugábamos a

11 Permítasenos rescatar un legajo inédito del manuscrito de Alamiro (1965), el primer relato de Couve, donde la muerte de Pablo Burchard interrumpe la escritura: "13 de julio. Hoy ha muerto don Pablo. Nada tiene trascendencia aparentemente en el día de los grandes acontecimientos. Resonancia tardía y gratuita; provechosa. A veces pienso que dios debiera perdonar a los grandes... [el texto no continúa]" (Manuscrito de Alamiro, sin núm.). No será, sin embargo, la última vez que la muerte se deslice, como un hito, al interior de la escritura de Couve. Cabe consignar que, comenzando el capítulo 5 de La lección de pintura, leemos anotado en el margen superior del cuaderno: "Hoy murió el alcalde de Santiago. Enero-79" (Manuscrito de La lección de pintura, sin núm.). Se refiere a la trágica muerte de Patricio Mekis, quien el 27 de enero cayó del balcón de su casa de veraneo. Además, este dato circunstancial nos permite reconstruir el ritmo de escritura de La lección: un tercio de la novela -desde la muerte de Mekis en adelante- se escribió en no más de cuatro días (el punto final fue puesto cuando todavía corría el mes de enero, según consta en la última página del manuscrito).

12 Parodias escolares, jugarretas: “No se piense que Aguiar era uno de esos individuos de quienes se dice que poseen un barniz de cultura [...]. Por el contrario, era Carlos Aguiar, más que barnizado, enchapado..." (177). 
dibujar a los profesores? ${ }^{12}$, ¿qué mejor manera de discutir la educación artística que a través de una novela de aprendizaje invertida, donde la lección de pintura brilla por su ausencia y la gran academia es un salón improvisado en una farmacia?

Ya desde su nombre, Carlos Aguiar lleva inscrita su función en el relato, cual mandato del destino (a-guiar): él será el guía del talento prematuro, su tutor, quien le señalará el camino a Augusto Medrano. Sin embargo, en contigüidad con el también farmacéutico Bechard (o Burchard), el apellido de Aguiar nos trae a la memoria el de otro maestro de la Escuela de Bellas Artes, Augusto Eguiluz (1893-1969), pintor de clara tradición cezanneana. Más todavía cuando leemos en la novela sobre las precisiones del gusto del tutor: "Su tema predilecto era el de la escuela impresionista" (177), y más tarde lo veremos en el Museo de Bellas Artes, contemplando, entre otros, las obras del modelo que inspira su figura: "[a]trayendo la atención del farmacéutico los óleos de Juan Francisco González, Eguiluz y Pablo Burchard, pintores afines a los artistas europeos que él tanto admiraba" (190; énfasis nuestro). La autoría nos dice que se trataba de un "farmacéutico de renombre" (177), y esa fama, más propia de un artista que de un farmacéutico, sugiere que existe otro relato más allá del literal. Eguiluz, Aguiar: como si al adoptar a ese niño pintor sin padre, el apellido se hubiera transformado gracias al espejo convexo de la fábula. Incluso, especulativamente, al seguir las consecuencias simbólicas del apadrinamiento de Carlos Aguiar a Augusto Medrano ("[e]l pupilo terminaba en las rodillas del viejo solterón..." [185]), advirtamos que juntando los nombres del pupilo y el maestro se forma "Augusto Aguiar" (acercándonos, todavía más, a la sombra de "Augusto Eguiluz" proyectada en el juego de los anagramas).

La narrativa de Couve trabaja los nombres propios como si fueran cuerpos, explota sus posibilidades plásticas, letra a letra -lejos estamos aquí, valga aclarar, de establecer identidades fijas, uno es a uno, sino más bien transitar por las afinidades de un correlato de las influencias que a veces se vuelve institucional, nacional e, incluso, internacional; estos son juegos de reconocimiento, pero también de engaño ${ }^{13}$. Ahora, bien, para nadie es un secreto que Couve, pintor, junto a su devoción

13 Como advierte Latham: “No es que aquellos que posean una clave [biográfica] tengan acceso a una historia públicamente acreditada anterior a la textualización. Más bien, se encuentran paradójicamente encerrados en un texto laberíntico, donde a pesar de estar en poder de la clave, no pueden estar seguros acerca de qué puertas conducen a los hechos y cuáles a la ficción" (14). 
discipular por Burchard ("El sol de Burchard alumbrará sus cuadros por mucho tiempo" [Couve, "Burchard", 73]), también fue ayudante del "taller de Augusto Eguiluz" (Díaz 9), cátedra que heredó después de su muerte. Apadrinamientos, maestros y discípulos, líneas de sucesión: "figuras patriarcales" de la educación artística chilena, como anota Pedro Zamorano, en su pesquisa histórica de la Escuela de Bellas Artes (209). El narrador de La lección de pintura apunta, malicioso: “[e]ntre el farmacéutico alemán y el señor Aguiar había un asunto pendiente que incomodaba a ambos. Se trataba del cuadro de un alquimista del siglo dieciocho [...]. Al venderse la droguería no se estipuló lo del retrato, y así, tanto el anterior [Bechard] como el actual propietario [Aguiar] se creían dueños del cuadro" (180). ¿Cómo habrán leído esos primeros lectores del departamento de Teoría la humorística escena del litigio por este cuadro imposible?, ¿acaso como la disputa por cuál de ellos era el dueño de la "alquimia", antigua ciencia que curiosamente está tan ligada al color (Montes 123) como a la química de esos dos "farmacéuticos" ?"14 Y, ciertamente, que se trate de un alquimista del siglo XVIII suena a una humorada: su versión preliminar, en cambio, decía "un alquimista medieval" (Manuscrito de La lección de pintura, sin núm.).

Leyendo el manuscrito, sin embargo, nos enteramos de que don Carlos Aguiar tuvo otro nombre, incluso antes de llamarse "Nicolás Aguiar". Y es que el primer nombre para el tutor de Augusto Medrano fue "Alfonso Bruce", que de haber permanecido en el texto habría sido el nombre más consonante con "Adolfo Couve" de toda su obra (quizá en compañía de la decrépita "Angélica Bow", de Balneario [1993]; y advirtamos cómo en ambos casos una B remplaza una C). Pero, ¿por qué Bruce? Por contigüidad, recordemos el nombre del padre de Couve: Adolfo Couve Braga, y pareciera que de la fusión de los dos apellidos paternos (Braga, Couve), surge el anagrama de "Bruce", es decir, las primeras líneas con las que se bosquejó al protector de Augusto Medrano. ¿No es este el verdadero laboratorio del alquimista, que transmuta la materia, los nombres y los puntos de referencia hasta hacerlos vagamente reconocibles, para finalmente diluirlos en el fondo falso de un episodio local de la historia del arte?

14 Leído de otro modo, puede que el litigio entre Aguiar y Bechard por el "alquimista" aún no esté del todo resuelto: "Pero cuando Simonetti junta a [Juan Francisco] González con Burchard, y a Burchard con Couve, manifiesta su deseo de hacer un negocio para el cual carece de presupuesto. No hay crédito disponible para esta operación. Confunde las historias. No hay tal continuidad entre Juan Fco. González y Pablo Burchard [...]. No comparten, por decirlo de algún modo, la misma "episteme". Pero tampoco la comparten Couve con Burchard, porque además, no es discípulo suyo, sino de Eguiluz" (Pastor Mellado, sin núm.; énfasis nuestro). 
De detenerse allí las asociaciones, este sería otro ejemplo más de cómo la obra de Couve deambula por el pacto ambiguo ${ }^{15}$; no obstante, el nombre tachado de "Alfonso" como figura paterna, seguirá latiendo en el texto definitivo, al reaparecer unas pocas líneas más abajo, desplazado, en una de las anécdotas que el señor Aguiar cuenta a su auditorio: “...los deleitaba con el cuento de la oreja que Van Gogh se cortó para ofrendarla a una querida, o el despotismo desplegado por el conde Alphonse de Toulouse Lautrec hacia su hijo deforme, y su arrogante actitud de acompañar de a caballo el féretro de su hijo en el día de su entierro" (177; énfasis nuestro). Es inevitable pensar aquí en el retorno de lo reprimido: porque si, en el caso de Couve, la autoría suprimió la relación filial entre "Alfonso Bruce" y el niño Augusto, esa relación ausente se espejea en la cita al "Libro de la vida de los grandes artistas", del que La lección de pintura aspira a ser su capítulo provinciano. Este es un espejo de simetrías negativas en que la pareja fantasmal de Alfonso Bruce (nombre inicial) y su protegido Augusto Medrano se reconoce en las vidas paralelas de Alphonse (Alfonso apenas disimulado en la ortografía francesa) y su hijo artista, que en lugar de ser gracioso como Augusto, resulta dolorosamente contrahecho. No por nada, Laplanche y Bertrand apuntaban que "[1]o reprimido utiliza, para su retorno, las mismas vías asociativas que siguió en la represión" $(388)^{16}$.

Advirtamos, entonces, que la imagen de padre e hijo renace en el texto de Couve arrastrando el signo ominoso de la violencia y la monstruosidad ("el despotismo desplegado por el conde Alphonse de Toulouse Lautrec hacia su hijo deforme"). Además de portar, claramente, la amenaza de la completa destrucción del artista ("[s]u actitud de acompañar de a caballo el féretro de su hijo"). Y el lector se pregunta si no es para poner coto a

15 Este es el término con que Manuel Alberca describe el espacio gris ubicado entre los dos compartimentos estancos y mutuamente excluyentes de la propuesta de Lejeune (el pacto autobiográfico y el pacto novelesco):“Como el niño en el juego [de la escondida], el adulto coquetea en el terreno de la confesión camuflada con [...] dos posibilidades antitéticas: esconderse tras un yo ficticio para no ser identificado y dejar, al mismo tiempo, las pistas justas, arriesgando sólo lo indispensable, para poder afirmar su yo íntimo frente a los demás sin exponerse al peligro de la sanción social" (80).

16 A propósito, es Jean Bellemin-Noël quien propone, quizá desde una concepción del texto un tanto rígida, que es en el manuscrito donde el crítico puede encontrar la palabra expulsada de la cadena significante, como si se tratara del inconsciente textual de la obra definitiva: "El analista puede interpretar un sueño, por ejemplo, sólo si la persona en el diván dice con toda libertad qué palabra en particular, qué personaje o escenario, o qué detalle lo hace detenerse a pensar. Ahora bien, un texto no puede responder más que con las mismas palabras que lo constituyen [...] [y] para el investigador no hay nada más valioso que una nueva palabra, una que prolongue la serie y dé luces sobre ella. Esa palabra, en general, ha sido reprimida: no hay dónde encontrarla, al menos no como un todo visible y legible. Pero ocurre que el avant-texte puede permitirnos encontrar ese término extraviado" (34; traducción nuestra). 
esta terrible escena filial que se superpone el encuentro entre el mentor maravillado (Aguiar) y el genio recién descubierto (Augusto). De ahí quizá el deseo de la autoría por reemplazar unas degradadas relaciones de consanguinidad por los roles putativos que ofrece la educación artística: en vez de Alfonso Bruce, Bechard (Burchard) y Aguiar (Eguiluz). Así, La lección de pintura, construida sobre un plan sencillísimo que va desde la manifestación del talento a la primera formación del niño, no hace más que pasearnos por roles elementales, casilleros claramente etiquetados, donde cada personaje, susceptible de ser permutado, vale más por su posición en el esquema que por su figura: padre (adoptivo), maestro o guía; hijo, discípulo o elegido ${ }^{17}$-anticipando aquí la vocación arquetípica que luego se desplegará en La comedia del arte con sus personajes sometidos al libre juego de la voluntad creadora, una vez que el artista logró, según el dictado de Picasso, escribir como niño.

Roles que todavía se vuelven más transparentes cuando revisamos los comienzos del protagonista de esta discusión sobre el status quaestionis de la educación artística chilena. Aquí surge uno de los hallazgos más interesantes de las enmiendas de La lección de pintura, al descubrir que en un momento previo, su protagonista era una dulce niñita llamada Sofía, antes de que, literalmente, la autoría le cortara el pelo y la rebautizara como Augusto $^{18}$. Permítasenos, esta vez, leer un pasaje del manuscrito in extenso, cuando se nos presentan los primeros pasos de una infancia solitaria, guarecida dentro de un barril mientras la madre trabaja:

Dentro del barril, la pequeña Sofía, apollada (sic) con dificultad en sus manitas, giraba a veces en redondo, intentando permanecer erguida, aunque su torpe andar la traicionaba y doblándosele sus débiles tobillos iba a dar al fondo junto a sus juguetes. Eso era al comienzo, cuando Elvira al regresar de sus andanzas la encontraba dormida en el fondo abrazada a su muñeca regalona [...].

Como la madre, era la niña de contextura muy frágil, pareciendo imposible que esas dos piernas flacas como hilos

17 En este mismo sentido, Leonidas Morales, en un seminario de postgrado de la Universidad de Chile dedicado a la narrativa de Couve (2011), ha estudiado provechosamente La lección de pintura a partir de las funciones propuestas por Vladimir Propp en Morfología del cuento.

18 En rigor, las transformaciones de género del protagonista de La lección de pintura siguen un oscilante camino, principalmente en las primeras páginas de la nouvelle: primero siendo niño (sin nombre) por un brevísimo espacio; luego, al pasar en limpio los primeros capítulos, niña (Sofía), para más tarde ser corregido nuevamente y quedar como Augusto. 
pudieran sostener el resto. Sobre todo el angosto cuello a la cabeza, de facciones regulares, en donde el pelo negro parecía más que recogido, pintado por lo tirante a que lo sometían un par de trenzas. La boca era diminuta y la nariz tan pequeña y roma que toda la expresión se la llevaban unos ojos alertas y precisos que no divagaban nunca (Manuscrito de $\mathrm{La}$ lección de pintura, sin núm.; conservamos ortografía; énfasis para resaltar los cambios).

Comparémoslo con la versión definitiva:

Dentro del barril, el pequeño Augusto, apoyado con dificultad en sus manitas, giraba en redondo intentando permanecer erguido. Eso era al comienzo, cuando Elvira, al regresar de sus andanzas, lo encontraba abrazado a un marinero de trapo [...].

Como la madre, el niño era de contextura frágil. Parecía imposible que esas dos piernecitas flacas como hilos pudieran sostener el cuerpo o, bien, el angosto cuello a la cabeza. De facciones regulares, el cabello negro semejaba pintado por lo sedoso, lo que lo hacía caer en un tupido fleco sobre la frente. La boca era... (La lección de pintura 175-6).

Cual retrato al óleo, las pequeñas pero sorprendentes correcciones se atienen exclusivamente a un criterio visual: el rostro de la pequeña Sofía no recibe más que retoques; y con dos pinceladas (una que corta las trenzas $^{19}$, otra que agrega un fleco, como también podría haber agregado un bigote), los rasgos que eran de niñita se convierten, conservando la mayoría de sus características, en las de Augusto Medrano. Si los cuerpos, los volúmenes, permanecen sin ser modificados, es porque aquí prima el imperio de las formas, no el de sus connotaciones; mientras que, en cambio, las identidades cambian con la plasticidad del trazo: niña en niño, "muñeca regalona" en "marinero de trapo", Sofía en Augusto.

19 Estamos tentados de recordar a los cortadores de trenzas, esos sujetos en los que Freud vio la quintaesencia del carácter fetichista (152). Porque bien mirado, el gesto minúsculo del narrador sobre las trenzas de Sofía resuena en los enunciados de agresividad y veneración de la poética de Couve: "[c]astigar el contenido y el lenguaje, intentar ese engranaje que da, más que un libro, un verdadero objeto" ("Prólogo"8). Después de todo, tanto el "manifiesto" de Cuarteto de la infancia como la voluntad de erigir perfectas miniaturas, hacen recordar la reacción ambivalente que despierta el ídolo en su dueño, "[1]a ternura y la hostilidad [simultánea] en el tratamiento del fetiche..." (Freud 152). Castigar el contenido y el lenguaje, pero al mismo tiempo adorar la diminuta joya del orfebre. 
Nuevamente, allí están los nombres: Sofía. Al tratarse a todas luces de una fábula sobre la educación artística y sus instituciones, aquí tenemos al "Saber" ${ }^{20}$ encarnado, el ideal ocupando el centro del escenario ("¡Dios Santo, este niño [a] es un genio!" [186]). El gesto de llamarla Sofía nos recuerda la construcción de las alegorías medievales, donde los personajes son llamados según lo que representan ("Prudencia", "Verdad", Vicio"), instruyendo al lector de qué manera debían ser interpretados. Sofía y A-guiar, ya sea desde la evidente etimología o los juegos del significante, son una muestra de cómo la obra de Couve está hecha a partir de roles más que de personajes, y de ahí que los cuerpos ingrávidos de Couve dejen traslucir el mundo de las ideas. No olvidemos de que esta Lección de pintura fue, en sus orígenes, una novela-tesis, acerca de consideraciones en torno a una crisis, como rezaba su subtítulo: el "Saber" junto a sus afectos y desventuras en las Academias de Bellas Artes; texto de amor filial y parricida a la vez. ¿Será porque evidenciaba demasiado el entramado argumental que el nombre de Sofía, tan sugerente, fue tachado? "La significativa alegoría del argumento desequilibraba el texto", dice el narrador de La comedia del arte sobre sus propias versiones tachadas en 1995 (363). Quizás justamente fue eso lo que se temió que ocurriera en 1979 con "Sofía", y se optó por Augusto, que en vez de evidenciar, disimulaba, volviendo la hechura del texto más novelesca -aunque su reemplazo por el nombre de un emperador romano (Augusto) no es precisamente neutro, menos aún en un país como Chile, sólo algunos años después del golpe militar.

Y, en efecto, el modo de composición de Sofía y Aguiar, el saber y su guía, son ciertamente un anticipo del sistema de equivalencias que insinuarán Camondo (la pintura), Marieta (la modelo) y Gastón Aosta (la fotografía), en el triángulo amoroso de La comedia del arte que transforma al pintor de caballete en Pierrot le fou: abstracciones encarnadas, alegorías montadas al interior de la provincia, al borde del mar. Incluso si consideramos las palabras con que Couve en 1979 justificaba los motivos de su novela-tesis ("[n]unca el arte de la literatura, como el de la música, han enfrentado la difícil crisis por la que pasa la pintura..." [21]), con semejante introducción era posible esperar tanto La lección de pintura

20 "Sofía", en este sentido, confirma y nos devuelve a la lectura de Cristian Montes Capó cuando señala que de las páginas de La lección de pintura puede extraerse "la idea de que el auténtico artista posee un talento natural y un conocimiento inmanente" (119), o una "sabiduría", podríamos complementar ahora desde el manuscrito. 
como La comedia del arte (novela donde la irrupción de la fotografía hacía entrar en crisis la relación amorosa del pintor y la modelo).

Finalmente, cabría preguntarnos: ¿dónde quedó la lección de pintura en La lección de pintura? Consideraciones en torno a una crisis: en esta novela de aprendizaje donde el título frustra las expectativas (un cenotafio), la ausencia de la lección esperada crece a la par del silencio con que el niño genio mira a los encargados de su educación artística (vidas envejecidas, destempladas, desorientadas). Una mirada insatisfecha, pero también compasiva. Al subir al tren que lo llevará de vuelta a Llay-Llay luego de una temporada en Viña del Mar, el joven Augusto contempla, por primera vez emocionado, a su profesora de pintura, Lucrecia Cortés (Rebeca en el manuscrito), mujer marchita y de mediocre talento: “... como si las reservas anteriores hubieran dejado paso a una admiración no sustentada en los valores artísticos, sino en otros más profundos y valederos" (206). Aquí no hay lección de pintura, y no la habrá, en vano buscará el lector en la relectura (es el vacío que amenaza con devorar el texto), pero compensatoriamente se nos ofrece algo mayor: La cátedra de la señora Rebeea, que era el título con que el manuscrito encabezaba este, el último capítulo de La lección de pintura. Buscando una sencilla lección, nos encontramos con una cátedra, no de pintura, sino de escepticismo, soledad y dominio de sí:

Y mientras Augusto observaba a esa pareja desde la ventanilla [Arnaldo de Morais y Lucrecia], de qué manera guardaban las apariencias [...,] el pecho del joven se ensanchó en un afán desmesurado por tenderle los brazos [a Lucrecia] y llorar en los suyos; pero ella, conocedora de lo que le acontecía, continuó sonriendo y gesticulando, haciéndole ver con aquellos aspavientos que debía aprender a dominar esos impulsos sentimentales, labor por lo demás de toda su vida futura (206-7).

La enseñanza recibida, después de todo, es una cátedra de contención expresiva que, ya lo sabemos, encuentra más de una correspondencia formal en el (auto) control que los narradores de Couve exhiben a lo largo de sus primeros textos. Dominar los impulsos sentimentales, castigar el contenido y el lenguaje, bajo la mirada de la profesora Rebeca (o Lucrecia); la escritura como un niño que hay que educar. El ejercicio de la corrección sobrepasa los límites de la letra para materializarse en la 
educación sentimental de un niño obligado a 'guardar las formas' -“labor por lo demás de toda su vida futura", dice el narrador y se escucha como un augurio-. ¿No es precisamente esa la "labor" del corrector y de cuyas huellas dan cuenta los manuscritos de Couve?

\section{Obras citadas}

Alberca, Manuel. El pacto ambiguo. De la novela autobiográfica a la autoficción. Madrid: Editorial Biblioteca Nueva, 2007.

Bellemin-Nöel, Jean. "Psychoanalytic reading and the avant-textes". Trad. Jed Deppman. Genetic criticism: texts and avant-textes. Ed. Jed Deppman et al. Philadelphia: University of Pennsylvania Press, 2004. 28-35.

Couve, Adolfo. "Alamiro". Manuscrito. 1965. Biblioteca Nacional, Santiago. 5 de agosto de 2013. URL: <http:/ / www. bncatalogo.cl/escritor/AE0022825.pdf $>$.

. "Burchard". Escritos sobre arte. Ed. Paz Balmaceda. Santiago: Ediciones Universidad Diego Portales, 2005. 73-75.

.La comedia del arte". Narrativa completa. Santiago: Seix Barral, 2004. 363-431.

. "La comedia del arte”. Manuscrito 1993. Biblioteca Nacional, Santiago. Consultado el 10 de junio de 2013. URL: <http: / / www. bncatalogo.cl/escritor/AE0020699.pdf>.

. "El cumpleaños del señor Balande". Narrativa completa. Santiago: Seix Barral, 2004. 293-303.

. "La lección de pintura". Narrativa completa. Santiago: Seix Barral, 2004. 173-207.

. "La lección de pintura". Manuscrito. 1979. Biblioteca Nacional, Santiago. Consultado el 10 de junio de 2013. URL: <http: / / www.bncatalogo.cl/ escritor / AE0022835. $\mathrm{pdf}>$.

. "La lección de pintura: consideraciones en torno a una crisis". Escritos sobre arte. Ed. Paz Balmaceda. Santiago:

Ediciones Universidad Diego Portales, 2005. 21-5. 
. "Prólogo". Cuarteto de la infancia. Buenos Aires: Seix Barral, 1996. 7-10.

Díaz, Gonzalo. "Nota sobre Couve". Escritos sobre arte. Ed. Paz Balmaceda. Santiago: Ediciones Universidad Diego Portales, 2005. 9-11.

Flaubert, Gustave. "À Louise Colet". 3 de abril de 1852. Carta. Centre Flaubert. Consultado el 23 de mayo de 2013. URL:

$<$ http: / / flaubert.univ-rouen.fr/ correspondance/conard / lettres / 52c. html>

Freud, Sigmund. "El fetichismo". Obras completas XXI. El porvenir de una ilusión. El malestar en la cultura y otras obras. Trad. José L. Etcheverry. Ed. James Strachey. Buenos Aires: Amorrortu, 1992. 141-152.

Hay, Louis. "Does 'text' exist?". Trad. Matthew Jocelyn. Studies in bibliography 41 (1988). 64-76.

. "Genetic criticism: origins and perspectives". Trad. Jed Deppman.

Genetic criticism: texts and avant-textes. Ed. Jed Deppman et al. Philadelphia: University of Pennsylvania Press, 2004. 17-27.

Latham, Sean. The art of scandal. Modernism, libel law, and the roman à clef. Oxford: Oxford University Press, 2009.

Laplanche, Jean y Jean-Bertrand Pontalis. Diccionario de psicoanálisis. Trad. Fernando Gimeno Cervantes. Buenos Aires: Editorial Paidós, 2004.

Lejeune, Philippe. "El pacto autobiográfico". Trad. Ángel G. Loureiro. La autobiografía y sus problemas teóricos. Coord. Ángel G. Loureiro. Barcelona: Editorial Anthropos, 1991.

Montes Capó, Cristian. "La idea de arte y de artista en La lección de pintura de Adolfo Couve". Anales de literatura chilena 10 (2008). 119-135.

Pastor Mellado, Justo. "Sobre la ausencia de una corriente analítica debidamente asentada en la escena chilena". Abr. 2003. Consultado 28 de mayo de 2013. URL: 
<http: / / www.justopastormellado.cl/escritos_ cont/semanal/2003/05_mayo/20030409.html>.

Stewart, Susan. On longing: narratives of the miniature, the gigantic, the souvenir, the collection. Durham: Duke University Press, 1993.

Toro, Felipe. "Una pieza secreta: juegos y juguetes en la narrativa de Adolfo Couve". Revista chilena de literatura 83 (2013). 177-195.

Valdés, Adriana. "Adolfo Couve, narrador de lo inquietante". Narrativa completa. De Adolfo Couve. Santiago: Seix Barral, 2003. 7-14.

. “El síndrome de Flaubert". Reseña (octubre 1989). 21.

Williams, Tony. "The writing process: scenarios, sketches and rough drafts". The Cambridge Companion to Flaubert. Ed. Timothy Unwin. Cambridge: Cambridge University Press, 2004. 165-179.

Zamorano Pérez, Pedro. “Educación artística en Chile: Fernando Álvarez de Sotomayor, Juan Francisco González y Pablo Burchard, tres maestros emblemáticos". Atenea 495 (2007). 185-211. 
